\title{
Economic and Environmental Factors in the Concept of Regional Sustainable Development
}

\author{
Naylya Amirova ${ }^{1}$, Lyudmila Sargina ${ }^{1}$, and Asiya Khasanova $^{1}$ \\ ${ }^{1}$ Plekhanov Russian University of Economics, Academic Departments of Political Economy and of \\ the History of Economic Science, 117997, Moscow, 36 Stremyanny lane, Russia
}

\begin{abstract}
Ultimately, the goal of economic development is to improve the quality and standard of living of the population. Today, this integral indicator is determined not only by economic parameters, but also by a number of other components, among which an important role is assigned to environmental ones. In this regard, theoretical and practical studies of reproduction systems come to the fore, which make it possible to guarantee economic growth with the preservation of natural and ecological potential in the face of aggravation of global problems of mankind. The issue of choosing a new model of economic development has been actualized for Russia, in particular, by the policy of sanctions and a reduction in export revenues. The circular economy fully meets all these pressing issues of our time, ensuring a reduction in the dependence of economic growth on the resource intensity of production and consumption, contributing to the economic and environmental development of Russian regions, while reducing the level of environmental pollution. This is especially true for regions which economy is based on mining. The article analyzes the economic and environmental factors influencing the formation and development of a closed-cycle economy as one of the new forms of management that ultimately contribute to the sustainable development of regions.
\end{abstract}

\section{Introduction}

Vector development of the modern economic model in the world, including Russia, towards the absolutization of economic growth to the detriment of solving social and environmental problems, as well as recent crisis, indicate the need for searching for a new path of economic development. Awareness of a general environmental catastrophe with its accumulated energy, which originated at the beginning of civilization genesis and rapidly developed in the subsequent period until the middle of the last century, has been growing rapidly since the second half of the XX century. It is felt not only by humans, but also by nature itself. The answer to these challenges of our time is the formation and development of new forms of management, associated, for example, with minimizing the waste producing and stimulating the long-term re-use of materials and resources in the economy. This idea is the basis of a circular economy, which is essentially a new model for the production and consumption of goods and services. 


\section{Materials and Methods}

The identification of patterns and the relationship of the economy with the reproduction of natural systems, as well as the search for ways to harmonize economic relations with the need for conservation of wildlife in the context of the concept of sustainable development in modern conditions can be defined as the most important problem of the whole world. Its solution of which allows to preserve the natural processes of evolution of nature and eliminate the discrepancy between the desired economic development of human civilization and the state of the environment. In particular, two new directions in the concept of economic development, such as sustainable development and human development, both based on humans, were generally accepted in the last two decades of the 20th century within the framework of the UN institutions. However, in practice, the preservation of the traditional type of economic development, characterized by a weak sensitivity to social and environmental problems, causes little progress in the implementation of these concepts in the modern world. Because of this, the economic "mainstream", characterized by the antagonistic interaction of society and nature, remains the basis of the development program in the countries of the world, including Russia. The implementation of the concept of the development of society, which would not contradict the universal laws of the evolution of nature, as well as take them into account and be consistent with them, would contribute, along with the possibility of solving environmental problems, to creation of more favorable conditions for meeting the needs of each individual and society in the long term [1].

Note that until the end of the 19th century, the limits of biosphere capacity were not violated by the large-scale human impact on the environment, which led to the absence of global catastrophes, not excluding, of course, the possibility of local and regional environmental crises. The prerequisites for giving the environmental problem the character of a global catastrophe can be attributed to two major factors. First, this is a demographic transition - a significant rate of population growth in Europe in the 18th-19th centuries and in the 20th century in Asia, Africa and Latin America. Therefore, only in Latin America there was $5 \%$ of the world's population, which amounted to 95 million people, and the figure of $13.5 \%$ characterized the share of the African population in the world population in 2000 . And, of course, the processes of industrialization and urbanization in the 19th century, accompanied by an increase in the production and use of coal, oil and gas and other both non-renewable and renewable resources.

\section{Results and Discussion}

At present, it is becoming obvious that the basis of the concept of development in the $21 \mathrm{st}$ century consists of priorities of sustainable development and a green economy. The essence of the most widespread and generally accepted interpretation of the concept of sustainable growth, which implies development that, along with meeting the needs of the modern generation, can eliminate the threat to the vital needs of the generation in the future, determines the presence of three dimensions of sustainable growth - economic, social and environmental. Note that the integrity of achieving sustainable development implies compliance with the requirements for each of these dimensions (table 1) [2].

Table 1. Components of sustainable development.

\begin{tabular}{|c|c|}
\hline Component & Description \\
\hline $\begin{array}{c}\text { Economic } \\
\text { development }\end{array}$ & innovation, improvement of risk management; \\
& employment of the population, professional development, business \\
\hline
\end{tabular}




\begin{tabular}{|c|c|}
\hline Social progress & $\begin{array}{c}\text { observance of human rights, investments in non-profit } \\
\text { organizations; } \\
\text { health, climate change control, biodiversity conservation. }\end{array}$ \\
\hline $\begin{array}{c}\text { Responsibility for } \\
\text { the environment }\end{array}$ & $\begin{array}{c}\text { efficient use of resources, production based on the principles of } \\
\text { sustainable development, product life cycle management; } \\
\text { preservation of clean air and water, "zero" waste, environmental } \\
\text { justice. }\end{array}$ \\
\hline
\end{tabular}

The achieved global consensus on development based on the principles of sustainable development in the 21 st century is evidenced by the adopted UN strategic documents. They combine both the priorities of sustainable development and a green economy in the world and Russia, and specific goals related to quantitative indicators, as well as a list of measures planned by the government. The set of these documents includes the following:

- a document on the prospects for humanity in the XXI century "The future we want", adopted in 2012 and defining a green economy as the basis for the concept of sustainable development;

- document on the UN Sustainable Development Goals for the period 2015-2030 - "The 2030 Agenda for Sustainable Development", adopted in 2015. Generally 8 goals for transforming the world out of 17 declared in the document include the ecological component of sustainable development;

- a document on the priorities of combating the threat to the climate around the world until 2030-2050 - Paris Climate Agreement, adopted in 2015. This document replaced the protocol of the Kyoto Agreement, which expired in 2020, and contains, including on the recommendation of Russia, the main directions for securing adequate accounting for the forest factor, as well as increasing the importance of global adaptation of all countries to climate change.

The increase in social needs in the process of evolution, associated with the provision and maintenance of constant rates of production growth, on the one hand, implies the development of the economy, and on the other hand, creates negative consequences for the environment. Humanity is increasingly aware of the critical exacerbation of the disproportion between economic development and environmental degradation, which necessitates the transition to sustainable development.

Addressing the realities of today allows us to get a complete picture of the scale of environmental problems. Against the background of degradation of ecosystems and depletion of natural capital on a global scale, over the past three decades, one can observe the growth of world GDP by more than four times, which contributed to an increase in the quality and standard of living of the population in the amount of several hundred million people [3]. The beginning of the XXI century was marked by a rapid growth of problems in the field of ecology: a shortage of fresh water and food of satisfactory quality; climate change as a result of the greenhouse effect and industrial emissions of carbon dioxide; threat to biological diversity; desertification, which implies the loss of a terrain of solid vegetation with the further impossibility of its restoration without human participation; overpopulation of the Earth, and many others [4].

Depletion of soil fertility on a global scale, on the state of which human life largely depends, as well as erosion and depletion of land areas lead to the degradation of more than $40 \%$ of the land. The continuing downward trend in land productivity may lead to the loss of half of the potential yield [5]. Along with this, the violation of sustainable soil fertility as a result of degradation will lead to a decrease in the ability to perform such important global functions of the soil cover: atmospheric, hydrospheric, lithospheric, general biosphere and biogeocenotic functions of the soil cover, habitat, living space of soil organisms and plants, 
sorption of mineral, organic substances and enzymes, preservation and maintenance of biodiversity and sanitary standards of life on Earth. In this connection, the nature conservation system itself becomes ineffective as a whole.

Practically all ecologists of the world recognize the problem of depletion of the planet's water resources. Of the total volume of water on the planet (about 1.4 billion cubic km), fresh water reserves are only $2.5 \% .780$ million people (of which $40 \%$ inhabit Sub-Saharan Africa) - and this is every tenth inhabitant of the Earth - lacks drinking water, which leads to the lack of access to adequate sanitation services for almost 1.5 million children under the age of 5 years. Along with this, by 2025, global water consumption will affect $90 \%$ of the world's fresh water resources against the backdrop of a growing trend in food consumption by $70 \%$ and water by $20 \%$. Almost $80 \%$ of the volume of virtual water (water "invested in goods") is accounted for by agricultural products [6]. However, almost one fifth of the world's grain producers use water unsustainably, causing a slowdown in agricultural growth and contributing to an increase in water scarcity. By 2030 , water supplies will meet only $60 \%$ of global needs.

The world's total forest area, covering about 4.06 billion hectares, or one-third of the land area, declined by 178 million hectares between 1990 and 2020. At the same time, as a result of the deforestation process, the annual loss of forests in the world amounted to 13 million hectares, which exacerbates the problem of providing the world's population with food, reduces the effectiveness of methods to combat poverty and climate change, and enhances desertification of lands in arid regions on an area of 3.6 billion hectares.

The persistence of such negative trends in the face of aggravation of global environmental problems over the next two decades will contribute to the development of extremely dangerous consequences for all of humanity and individual countries. At the moment of reaching the threshold indicators of the state of the environment, which necessitate the emergence of new restrictions on economic growth of an extensive type, the demand for resources will grow exponentially against the background of an increase in the world's population by $28 \%$ to 9 billion people, and the number of middle class consumers by 3 billion people. Subsequently, we should expect an increase in demand for food by $50 \%$, energy - by $45 \%$ and water resources - by $30 \%$, which will lead to an increase in world food prices and a decrease in the quality and standard of living of hundreds of millions of people. The demographic crisis and the problem of a shortage of resources capable of ensuring the livelihoods of an increasing number of people on the planet contribute to the exacerbation of the problem of the negative impact of production and consumption waste on the system of environmental equilibrium. Along with the fact that today almost 800 million people are starving in the world, more than 1 billion tons, or a third of all food, ends up in landfills and incinerators every year. The negative indicators of statistics on hungry will continue to grow, primarily at the expense of developing countries, and high-income countries will be the main polluters of the Earth. Thus, more than $15 \%$ of the population with the highest income generates about $33 \%$ of all waste on a global scale. By 2025, the indicator of the annual volume of garbage generated will increase by $70 \%$ [7].

Rational use of natural resources in the exploration of deposits, extraction and processing of minerals is the basis for the sustainable development of mining regions. At present, one can observe the processes of a significant intensification of mining, which contributes to an increase in the influence of the activities of mining enterprises on the environment and changes in the landscape of the area. The increase in costs in this type of economic activity even in the context of the development of mining technologies today is due to the fact that historically, mining was carried out first from easily accessible deposits with a high content of the useful component, and then affected the development of hard-to-reach deposits with a lower content of the useful component. Moreover, the supply of a large part of the volume of mineral raw materials to the world market by countries with an underdeveloped 
institutional base in the field of quality requirements and control of mining safety and the remote territorial location of mining production in the absence of adequate infrastructure also contribute to an increase in the costs of mining operations. Therefore, multilateral accounting of both economic and environmental aspects in the context of a rational approach to the creation of mining projects and the existing technical potential will make it possible to contribute to the sustainable development of mining regions by achieving an environmental balance.

High rates of profitability and efficiency in the short term of mining enterprises in Russia are provided by the demand for energy resources in foreign markets along with relatively high prices. However, as studies show, for example, in the current conditions of the development of Russian coal industry, which is at the point of no return, the long-term increase in production funds and investment in them becomes ineffective. Thus, maintaining competitiveness in the world market in the third decade of the 21 st century is possible only if projects are developed and implemented based on an analysis of the links between labor productivity, investment in fixed assets and the volume of fixed assets of the coal industry, which imply an increase in labor productivity by an average of 4 times [8]. The reorientation from extensive economic growth, the essence of which is the process of involving new natural resources in economic activities, should be carried out on the basis of the implementation of the principles of sustainable development strategy at mining enterprises. The design and implementation of mining projects should involve consideration of consequences of decisions that will be made in the economic, social and environmental spheres, along with the ability to assess costs, benefits and risks. Implementation of the principles of the justification of the enterprise's activities with a greater integral effect from production in comparison with the negative consequences and damage, improving the quality of labor, sustainability of ecosystems, subject to limiting the impact on the environment - all these will ensure the long-term efficiency of mining enterprises [9].

Russia possesses about 33\% of the world's coal reserves: lignite, bituminous and anthracite, and the coal industry is one of the largest in the fuel and energy complex of Russia. Ever since the beginning of the development of the coal industry during the reign of John III Vasilyevich the Moscow Great-Prince in the second half of the 15th century and then throughout the entire period of the industry's development, coal production indicators were indicators of the country's industrial development. Today, the basis for the functioning of the city-forming enterprises of the regions, the main activity of which is mining, is the level of technology development and environmental safety, which determine the development of almost all spheres of human life, including the standard of living of the population of these regions. According to the Program for the Development of the Coal Industry for the Period up to 2030 in Russia, the introduction of new and modernized capacities in the amount of more than 500 million tons, it is planned to increase coal production by 5 times compared to 2010. Reducing the costs of enterprises by using domestic technologies and equipment, improving solutions in the field of scientific, technical and innovative developments, maintaining the equilibrium of ecosystems in locations of coal mining enterprises as a result of the Program will help maintaining the competitiveness of the Russian coal industry in the current geopolitical conditions [10].

The Kemerovo Region, Krasnoyarsk Territory, Irkutsk Region, the Republic of Khakassia, the Trans-Baikal Territory, as well as the Republic of Yakutia, being the leading regions in coal mining, make the largest contribution to the volume of coal production, which today is 440 million tons. Development of coal-profile enterprises is characterized by functioning 58 mines and 133 open-pit mines, $50 \%$ of which were put into operation after 2020, an increase in investments in fixed assets of production by more than 2 times, the introduction of about three hundred million tons of new coal mining capacities. At the same time, an increase in the share of Russia in international coal trade 
by $5 \%$ from $9 \%$ to $14 \%$ over the past ten years allowed Russia to take the third place in the world market after Australia and Indonesia.

In the context of the problem under study, it should be noted that environmental innovations play a significant role in the process of achieving sustainable development of the regions where coal industry enterprises are present, the largest share of costs for which falls on the coal mining industry, and the indicator of which is more than $70 \%$.

However, it is generally known that the coal mining industry is considered one of the most "environmentally dirty" in the field of assessing the negative anthropogenic impact of the activities of mining enterprises on the ecosystem and living conditions of the population geographically located in the immediate vicinity of such industries. Thus, the share of the extractive industry in the violation of the ecological balance system is more than $60 \%$. At the same time, the demand for coal in the world fuel and energy balance may fall by $2 \%$ from today's $27 \%$ to $25 \%$ due to the aggravation of the fight against global warming and the increase in inter-fuel competition [11].

Throughout the entire production cycle of coal mining, problems arise on the way of implementing the concept of sustainable development, which are associated with minimizing the depletion of non-renewable resources, environmental pollution and the assessment of environmental consequences, and the efficiency of resource use.

It is well known that one of the main factors of global warming is burning of coal as a fuel at coal power plants, which is explained by a fairly large emission of greenhouse gases per $\mathrm{kWh}$ of electricity generated and a high concentration of emissions of a number of hazardous compounds (for example, $\mathrm{NO}_{\mathrm{x}}, \mathrm{CO}_{2}$ ) during these processes. Thus, within the framework of the 2019 New Green Agenda, based on a set of EU laws and regulations, phased transboundary carbon regulation is being introduced from 2021. Against the background of the decision to reduce greenhouse gas emissions by $55 \%$ by 2030 and a complete ban on emissions by 2050 , a duty is imposed on goods imported into the European Union, in the production cycle of which significant $\mathrm{CO}_{2}$ emissions are carried out. The amount of the duty for each ton of carbon dioxide emissions will be $\$ 30$. Considering the fact that Russia ranks fourth in the world in $\mathrm{CO}_{2}$ emissions after China, the United States and India, we can talk about financial losses to Russian exporters of the oil and gas sector, mining, metallurgical and chemical industries. Additional financial burden in the period 2025-2030 in these areas of production will amount to 33.3 billion Euros [7].

In modern conditions, there is no need to talk about alternatives to the use of coal in the energy sector, especially in developing countries. Maintaining the demand for coal in the market of alternative energy sources is possible only with a certain ratio of two competitive key parameters of the energy carrier - cost and environmental friendliness.

The implementation of the directions of the concept of sustainable development within the framework of economic, social and environmental goals based on the development of a circular economy can be a response to existing challenges in solving the problem of a natural disaster. According to forecasts, with the development of an economy based on the "take, make, reuse" chain, there will be a tendency to reduce carbon dioxide emissions by almost $50 \%$ by 2030 and by more than $80 \%$ by 2050 . Realization of the properties of a circular economy will allow the transition to a rational model of consumption and production, ensuring a reduction in the dependence of GDP on resource extraction. Thus, the functioning of new business models in a circular economy will reduce resource consumption, taking into account the specifics of the industry and the applied level of technologies, by $50-90 \%$, will lead to a decrease in waste by $87 \%$, and will reduce massive emissions of carcinogens and harmful substances by more than $90 \%$ [4].

In connection with the acute relevance of support of this modern trend - the development of a circular economy - Russian President indicated that the issue of the socalled extended environmental responsibility of manufacturers is also becoming the most 
important strategic task of achieving the efficiency and competitiveness of Russian products in the long term. Among the measures taken in recent years, which are aimed at achieving a balance in the economic, social and environmental aspects, it is necessary to include the implementation of the national project "Ecology" for the period from 2019 to 2024 , the purpose of which is to implement the principles of sustainable development.

However, financing of measures aimed at intensifying the transition from a linear to a circular economy in Russia in comparison with advanced countries in this matter can be considered insufficient. Thus, the volumes of expenditures on environmental protection and investments in fixed assets directed to nature conservation are characterized by indicators of $0.8 \%$ of GDP and $0.9 \%$ of GDP, respectively. At the same time, the EU budget provides for a figure of $20 \%$ of GDP to finance projects to mitigate the effects of climate change, develop and implement environmental innovations, and develop the transport and energy structure. In addition, the amount of funding for National Project "Ecology", determined at more than 4 trillion rubles, was spent only by $63.3 \%$, and for the first half of 2021 , expenses were fulfilled by $21.8 \%$ [7]. At the same time, it is noted that within the framework of the National Project, there is a flaw in issues of climate change, maintaining sustainable soil fertility and ensuring the economic security of waste disposal. Thus, despite the measures taken in the country aimed at achieving economic and environmental balance, it should be noted that there is little progress in reducing the pressure on the environmental balance system.

The scale of the problems associated with the implementation of the principles of sustainable development made it necessary to consolidate forces and approaches to their solution. The transformation of socio-economic relations in Russia based on the principles of sustainable development should involve the phased development of short-term, mediumterm. Long-term measures in the field of reducing negative environmental effects, creating additional jobs, reducing the polarization of developed and developing countries, requires special development and justification, which is beyond the scope of this research topic [11].

\section{Conclusion}

In any area of human activity, there is a concept of sustainability. Analysis of development prospects, forecasting the consequences of the results of socio-economic relations contribute to an increase in the efficiency of the economic system. A significant place is occupied by the study of problems associated with economic growth and the implementation of environmental policy directions, which is due to the orientation of the production and economic activities of the subjects towards the extension of consumption and use of the natural resource potential of the biosphere during the operation of the technological platform of production. The stability of the economic system, the high quality and standard of living of the population, the reduction of its differentiation in terms of income, as well as the national security can be guaranteed only by reducing the technogenic impact on the environment and assessing consequences of economic activities when making any managerial and implementation decisions.

The development of the economy based on the principles of sustainable development concept, along with the achievement of economic efficiency, requires high organizational, investment and operational costs, which must be justified in technological, regulatory and economic measures. It must be said that there are difficulties in forming a national strategy for sustainable growth due to the high differentiation of the country's regions. The development of road maps, the activities of which should take into account the spatial nature of the problems of the regions in the environmental, economic and social areas, will make it possible to conduct a qualitative assessment of the benefits and costs as a result of a phased strategy for the implementation of sustainable development principles. It has a special 
importance for regions where the basis of economic growth is the activities in mining industry

Note that radical transformations will not be successful without the preparedness of society's consciousness to understand the wasteful principles of linear models of production and consumption.

\section{References}

1. N. Amirova, L. Sargina, A. Khasanova, N. Amirova, L. Sargina, A. Khasanova, E3S Web Conf. 174, 02011 (2020).

2. N.E. Bondarenko, T.P. Maksimova, O.A. Zhdanova, Espacios 38(62), 2 (2017)

3. E.Yu. Dotsenko, N.P. Ezdina, S.V. Mudrova, E3S Web Conf. 41, 04050 (2018)

4. O. Kalenov, S. Kukushkin, E3S Web Conf. 174, 02024 (2020)

5. A.V. Kaplan, T.V. Davydova, O.A. Gribkov, Metallurgist 55(5-6), 459-462 (2011)

6. K. Ksenofontova, Journal of General Management 21(179), 37-39 (2020)

7. S. Kukushkin, O. Kalenov, R. Kamanina, O. Kosareva, E3S Web Conf. 174, 04014 (2020)

8. T.P. Maksimova, T.G. Bondarenko, O.A. Zhdanova, G.H. Harutyunyan, Scientific Papers. Series: Management, Economic Engineering and Rural Development 20(3), 353360 (2020)

9. N.V. Pahomova, K.K. Rihter, M.A. Vetrova, Bulletin of Tomsk State University. Economy 33(2), 244 (2017)

10. O.E. Ryazanova, V.P. Zolotareva, Lecture Notes in Networks and Systems 84, 101-106 (2020)

11. N.Yu. Sorokina, R.V. Gubarev, N.E. Bondarenko, T.P. Maksimova, Espacios 39(27), 3 (2018) 